What is the influence of cultural capital on student reading achievement in Confucian as compared to non-Confucian heritage societies?

Cheng Yong Tan

Faculty of Education, The University of Hong Kong, Hong Kong

Dian Liu

Faculty of Social Sciences, University of Stavanger, Norway

Cheng Yong Tan

Faculty of Education, The University of Hong Kong

Room 519, Meng Wah Complex, The University of Hong Kong, Pokfulam, Hong Kong

E-mail: tancy@hku.hk; learnsing@yahoo.com.sg

Phone: (852) 39174635

Cheng Yong TAN (PhD) is Assistant Professor in the Faculty of Education, The University of Hong Kong. His research interests include socio-economic status, cultural and social capital, Asian and Western parenting, academic achievement, self-efficacy beliefs, and school leadership.

Dian Liu

Faculty of Social Sciences, University of Stavanger

Room 303, Elise Ottesen-Jensens Hus, University of Stavanger, 4036 Stavanger, Norway

E-mail: dian.liu@uis.no

Phone: (47)5183 2927

Dian LIU (PhD) is Associate Professor in Faculty of Social Sciences, University of Stavanger. Her research interests are parental involvement in education, alignment between higher education and labour market, graduates' employability, and entrepreneurship study.

Corresponding author: Cheng Yong TAN

This study is supported by a Faculty Research Fund from The University of Hong Kong. 


\section{What is the influence of cultural capital on student reading achievement in Confucian as compared to non-Confucian heritage societies?}

The present study compared the contribution of familial cultural capital to the reading achievement of 116,508 15-year-old students who participated in Programme for International Student Assessment (PISA) 2012 in six Confucian heritage cultures (CHCs) and nine non-CHCs with comparable educational and economic development. The different states of cultural capital examined comprised institutionalized (maternal, paternal education) and objectified (educational, cultural resources) indicators. Results showed that (a) cultural capital levels were lower in CHCs (vis-à-vis non-CHCs); (b) cultural capital was generally positively related to student achievement in CHCs and non-CHCs; (c) the relationships between all cultural capital indicators, except educational resources, and achievement were weaker in CHCs than non-CHCs; and (d) objectified (vis-à-vis institutionalised) cultural capital was more strongly associated with achievement in CHCs. These results suggest that the stronger sociocultural emphasis on education in CHCs may have moderated cultural capital effects on student achievement and enabled more students to succeed academically.

Keywords: cultural capital; reading achievement; Confucian heritage cultures 


\section{Introduction}

Issues of social stratification and reproduction have attracted the attention of policymakers, educators, and researchers worldwide, especially in developed countries (Winkle-Wagner 2010). It is therefore not surprising that scholars have examined and debated the role of schools, families, and sociocultural values in contributing to social inequality in student school achievement, itself being a predictor of subsequent socioeconomic outcomes in life (Baker, Goesling, and Letendre 2002; Byun, Schofer, and Kim 2012; Caro and Lenkeit 2012; Ker 2016; Lee 2014; Zhang, Khan, and Tahirsylaj 2015). In particular, some scholars have employed Bourdieu's cultural capital theory to highlight how higher socioeconomic status (SES) parents equip their children with the requisite values and dispositions that are preferred in schools and that which contribute to school success (Winkle-Wagner 2010). In the process, these parents are argued to have transmitted their socioeconomic advantage to their children and perpetuated their dominant status in society.

Notwithstanding the utility of the cultural capital as an explanatory heuristic, countries vary in their sociocultural values and education systems. Therefore, it will be naïve to assume that cultural capital exerts a similar influence on student achievement in different contexts (Caro and Lenkeit 2012; French, French, and Li 2015; Ker 2016; Mendez 2015; Zhang et al. 2015). For example, one category of countries that have caught international attention are the so-called CHCs comprising Hong Kong, Japan, Korea, Macau, Shanghai, Singapore, Taiwan, and Vietnam. These CHCs have high levels of average student achievement in international assessment such as PISA, and therefore attract the attention of many policymakers and researchers attempting to unravel the secret of their educational success (Han and Makino 2013; Zhang et al. 2015). At the same time, there is a noticeable societal premium on education for social mobility and economic development in these countries. For example, the Singapore government has committed considerable resources to level up all (not just elite) 
schools, and provide generous educational bursaries and scholarships for needy and outstanding students (who may also come from disadvantaged families). In Hong Kong, the government has provided for free 12-year education for all to enable as many students as possible to receive a basic level of education. Student tracking has also been moderated (reduction from five to three ability bands in public secondary schools) following recent years of educational reforms to provide more inclusive learning experiences (Hong Kong Education Commission 2000). In Korea, institutionalized characteristics of the education system including a standardized curriculum, preoccupation on test preparation, and pervasive private tuition, coalesce to moderate the contribution of children's cultural capital on their academic achievement (Byun et al. 2012).

The question is then whether cultural capital theory can be applied to explain student achievement in $\mathrm{CHCs}$ as compared to non-CHCs given that the societal emphasis on education may moderate the impact of family cultural resources in CHCs. Therefore, the objectives of the present study are to (a) compare the relationship between cultural capital and student reading achievement in CHCs and non-CHCs with comparable levels of educational and economic development; and (b) identify which indicators of cultural capital are most associated with student achievement in CHCs. Reading achievement is the dependent variable of interest because it is more susceptible to familial influences as compared to mathematics or science, and because reading is often associated with highbrow cultural practices of higher SES families (Tan 2017). The study will examine international data from the PISA 2012 which comprise student and family information from CHCs and non-CHCs.

\section{Cultural capital in Bourdieu's theory}

The term 'cultural capital' is borrowed from Pierre Bourdieu's theoretical framework which also includes other related concepts such as field and habitus in mapping out the 
mechanism of social reproduction. Capital comes in varied forms such as economic capital, social capital and cultural capital (Bourdieu 1986). These concepts are aligned closely with each other. To illustrate, economic capital (e.g., household assets and income) can be converted into social capital (e.g., inviting social networks for gatherings at country clubs and obtaining valuable information from these networks on child's educational opportunities) and cultural capital (e.g., purchasing expensive musical concert tickets). With regards to the latter form of capital (the focus of this paper), different fields (as characterized by their own set of commonly shared rules, values, opinions, and systems of social relations) may moderate the relationship between cultural capital and children's outcomes. High SES parents therefore imbue in their children the requisite habitus comprising dispositions, actions, and thoughts that enable the latter to profit in the field of competition (Bourdieu and Passeron 1977).

Cultural capital comprises three states: objectified, institutionalized, and embodied (Bourdieu 1986). Objectified cultural capital represents the physical cultural resources owned by a person or a household that are aligned with the types of dispositions, values, perceptions, knowledge, and skills that teachers emphasize in schools (Tan 2017). Notably, the possession of objectified cultural capital, according to Bourdieu, is a method of production other than assumption, which allows this cultural-resource possession to be established by certain social groups. The present study examined two indicators of objectified cultural capital, namely student access to educational (e.g., books, computer) and cultural (e.g., art works, musical instruments) resources at home. There is some research evidence that higher SES students who had greater access to these resources had higher levels of academic achievement (Chiu and McBride-Chang 2010; Claro, Cabello, Martin, and Nussbaum 2015; Iruka, Dotterer, and Pungello 2014). For example, Claro and colleagues' (2015) study of eighth graders in Chile found that home availability of study desks, study areas, computers, educational software, and Internet connection was positively associated with their mathematics and reading achievement. 
However, some studies did not find a significant relationship between home educational resources and achievement. For instance, Lenkeit, Caro, and Strand (2015) found that home possessions partly explain the academic performance of immigrant but not native students in England. Hansson and Gustafsson (2013) also reported mixed results in that books at home contributed to the academic achievement of Swedish but not foreign students in Sweden. Institutionalized cultural capital refers to cultural capital that is credentialed and acknowledged as markers of social status, such as certificates obtained from schools (Bourdieu 1986). Due to the nature of cultural capital in the field of academia, any cultural capital obtained through educational qualifications is lost with the passing of the individual, while institutional cultural capital is independent of persons, formed through a collective move to impose recognition of cultural capital within academia. This institutional independence allows comparisons between individuals holding said academic qualifications, as well as between the earned cultural and economic capital, as academic capital guarantees a form of economic value on the labour market. This leads to a dependence on the value on the labour market when individuals choose to invest in academic qualifications (Bourdieu 1986, 1990). Institutionalized cultural capital can be measured by maternal and paternal educational attainment. There is evidence that students whose parents were more highly educated had higher levels of academic achievement (Baker 2014, 2015; Baker, Cameron, Rimm-Kaufman, and Grissmer 2012). For example, Baker and colleagues's study of African-American kindergartener boys found that maternal educational levels were positively associated with children's mathematics and reading achievement (Baker 2015; Baker et al. 2012). However, there are also studies that reported contrary results. For example, Zhao, Valcke, Desoete. and Verhaeghe's (2012) study of primary school students in China found that both paternal and maternal educational levels were not related to their children's mathematics achievement. 
Embodied cultural capital represents the knowledge, skills, quality or even awareness affiliated with individuals through social or educational activities, such as communication between parents and children, parental guidance in schoolwork, parental aspirations towards children's achievement, or home cultural/social activities (Tan 2017). The acquisition of embodied cultural capital is a time-consuming process in which individuals invest in and activate their resources (Bourdieu 1984, 1986; Grenfell 2007). Given that the acquisition of embodied cultural capital is difficult to recognize in nature, studies mostly measure this state of cultural capital by justifying the cultural distinctions of individuals. Given that what is deemed to be embodied cultural capital is more likely to vary according to field conditions in different countries, the present study will focus on examining less context-dependent states of cultural capital using objectified (home educational and cultural resources) and institutionalized (paternal and maternal educational attainment) indicators to enable meaningful comparisons between $\mathrm{CHCs}$ and non-CHCs.

\section{Student academic achievement across cultures}

It is naïve to assume that cultural capital contributes to student academic achievement in the same way across different societal contexts for various reasons. First, cultural capital may be represented by myriad indicators in different contexts (Caro, Sandoval-Hernández, and Lüdtke 2013; Rutkowski and Rutkowski 2013). For example, Caro and colleagues' (2013) study found that a comprehensive measure of economic, social, and cultural capital was somewhat perceived differently by participants in some of the 42 educational systems from Progress in International Reading Literacy Study (PIRLS) 2006 and the 14 educational systems from PISA 2009. Furthermore, the researchers found that cultural possessions could function as both economic and cultural capital, and parental literacy activities as both social and cultural capital indicators simultaneously to predict student achievement. In the same vein, 
Rutkowski and Rutkowski (2013) examined the psychometric properties of the home possessions index used in PISA 2009 to measure SES. Their results showed that the same index exhibited variable reliability among the 65 countries compared.

Next, societies may differ in variables such as levels of educational and economic development (Byun et al. 2012; Ker 2016; Lee 2014; Zhang et al. 2015), and these variables may either bear on student achievement or moderate the effects of cultural capital on student achievement. For example, more economically developed countries, as measured by their higher levels of Gross Domestic Product (GDP), may be able to commit more resources to education in terms of hiring and professional development of quality teachers, educational materials, and infrastructure in schools (Hanushek and Woessmann 2017; Heyneman and Loxley 1983; Little and Rolleston 2014). The higher levels of educational resources may then facilitate student achievement.

Education systems may also vary according to the levels of autonomy schools enjoy (Mourshed, Chijioke, and Barber 2010). Mourshed and colleagues (2010) attempted to classify education systems as belonging to one of four stages of development, from the least performing ('poor to fair') characterised by the central education authorities providing support for lowly skilled teachers in order to reach minimum standards for student achievement, to the best-performing ('great to excellence') marked by the central education authorities merely facilitating innovation and change emanating from schools and highly qualified teacher professionals.

Politics and history could also influence the developmental trajectory of curricular emphasis on some subject areas more than others (Dennis 2000). In terms of state intervention in education, many education authorities promote the salience of mathematics and science over liberal arts to prepare the workforce for the so-called knowledge-based economies where workers need to have a good mastery of mathematics and science knowledge, competencies, 
and skills to exploit exciting science, technology, engineering, and mathematics job opportunities (e.g., Tan 2013). The contents emphasized in school curricula may also be indicative of political endorsement of certain ideologies in the historical development of the subject area. Some scholars also attribute the high student achievement in CHCs to test preparations and paternalistic governance ideologies leveraging on the appeal of the societal premium on education and filial piety to foster learning in students (Byun et al. 2012; Dennis 2000; Tan 2013).

Societies could also have different mean levels of student achievement because of their sociocultural values related to education and learning. In particular, there is a group of countries - CHCs - that are generally characterized by high average levels of student achievement, relatively well developed education systems, and high societal emphasis on education for social mobility and economic development (Ker 2016; Lam, Ho, and Wong 2002; Lee 2010; Rao, Cheng, and Narain 2003; Tran 2013; Zhang et al. 2015). There are many cultural values in CHCs that promote student achievement. First, there is a sociocultural belief that effort and hard work is as important as innate intelligence in learning, and that perseverance in academic pursuits is an important part of one's lifelong moral cultivation (Sun 2011; Wang, Harding, and Mai 2012). Second, learning is regarded as an endeavour that will yield long-term benefits (e.g., better life prospects and social mobility) as opposed to hedonistic pursuits for immediate gratification (French et al. 2015). Third, academic and subsequent career achievement may be regarded as a filial responsibility to honour one's parents (Chan, Bowes, and Wyver 2009; Li, Costanzo, and Putallaz 2010).

These sociocultural values help at least partially explain why many students in CHCs are deferential to parents and teachers, as evidenced by research findings that allude to the positive association between authoritarian parenting or classroom teaching styles (respect for authority) and student achievement (Lee 2010). This respect for authority then translates to 
better overall student learning climate in schools and at home, thereby benefiting student learning. Some scholars have even argued that the myriad pro-learning cultural values serve to influence and inform parental and even government priorities in maximizing educational opportunities for all students in CHCs (French et al. 2015; Ker 2016; Lam et al. 2002; Nguyen, Terlouw, and Pilot 2006; Rao et al. 2003; Tran 2013).

It is therefore plausible that the contribution of family advantages (e.g., cultural capital) on student achievement in $\mathrm{CHCs}$ is smaller than that in non-CHCs, given the moderating influence of pro-learning cultural values. There is burgeoning evidence in support of this hypothesis. For example, Lee (2014) compared the association between different variables and student reading achievement for five CHCs (Shanghai, South Korea, Hong Kong, Singapore, and Japan) and eight other non-CHCs (Finland, Canada, New Zealand, Australia, Netherlands, US, UK, and Germany) using PISA 2009 data. Results showed weaker correlations between three SES/cultural capital variables and reading achievement for the CHCs as compared to non-CHCs. More specifically, student enjoyment of reading and student diversity in reading (both being aspects of cultural capital) and SES (measuring student home educational and cultural resources and parental educational levels among others) correlated with reading achievement at $.40, .16$, and .28 respectively for CHCs (vis-a-visa $.47, .24$, and .34 respectively for non-CHCs). Despite these tentative findings, the cross-cultural research on the contribution of cultural capital to student achievement remains tentative at best. This is because there is no evidence that previous studies have made valid comparisons of $\mathrm{CHCs}$ and non-CHCs that have education systems of comparable quality or comparable levels of economic development. Many of these studies also do not include for covariates at the student, school, or country level. The inadequacy in research design threatens the validity of findings reported. 


\section{The present study}

The preceding review suggests that it is not one but a constellation of social, economic, political, historical, and cultural factors that may explain why societies are marked by different mean levels of student achievement. Studies that do not address these contentions adequately may suffer from the fallacy of naïve empiricism (Juslin, Winman, and Olsson 2000). The present study acknowledges these issues, and attempts to mitigate the validity threats as much as possible by comparing the relationships between cultural capital and student reading achievement in $\mathrm{CHC}$ and non- $\mathrm{CHCs}$ that are as well matched as possible in key dimensions using publicly available data (e.g., on levels of educational and economic development), and by statistically controlling for some of these factors (e.g., levels of autonomy enjoyed by schools and national economic development levels) in the statistical analysis. The goal is to allude to sociocultural values on education and minimise competing factors that may account for student achievement differences between $\mathrm{CHCs}$ and non-CHCs.

Given the differences in prevailing sociocultural values, CHCs versus non-CHCs may be regarded as distinct social fields each operating with different rules of the game (or logic of practice). In particular, students from higher SES families in CHCs versus those in non-CHCs may benefit from either different repertoire of cultural capital or benefit differently from a given set of cultural resources. The present study examines the latter situation by comparing the effects of the same set of cultural capital indicators in CHCs and non-CHCs. This approach enables us to compare the relationship between the same set of cultural capital indicators and student achievement across the two types of countries. 


\section{Method}

\section{Participants}

The present study analysed data collected in PISA 2012 (OECD, 2013). Participants in PISA 2012 were selected to represent the complete population of 15-year-old students who were attending public or private schools in grade 7 or higher in the participating countries. PISA 2012 measured 15-year-old students' proficiency in applying their knowledge and skills learned in mathematics, science, and reading to authentic problems. In addition, PISA also collected data from students and parents regarding their educational experiences and attitudes, and from school principals on school demographics, policies, and practices.

For the purposes of the present study, participating countries in PISA 2012 which had high levels of student academic achievement and which had comparable levels of national income were analysed. More specifically, in terms of student academic achievement, these countries must have student mean levels of reading, mathematics, and science achievement that were equal to or higher than the Organisation for Economic Cooperation and Development (OECD) mean levels (see OECD 2013 for country-level results). PISA 2012 provided additional data on the proportion of low and high performers in mathematics for each country, so additional criteria for inclusion in the analysis were that countries must have a proportion of low mathematics achievers that was lower than the OECD average, and a proportion of high mathematics achievers that was higher than the OECD average. These data on mathematic achievement for the identification of comparable countries for analysis although the dependent variable of interest was reading achievement because they provided extra information on the overall performance of education systems. The use of the multiple inclusion criteria yielded 17 countries for analysis. However, an examination of the income levels of these countries showed that all, except Liechtenstein where income data was not publicly available, were classified as high or very high-income countries (OECD 2015; World 
Bank 2015). Liechtenstein was therefore excluded from the analysis because it was not possible to determine if it had similarly 'high' or 'very-high' income levels as the other countries. Shanghai, was also excluded because it might not be representative of all cities as regions in China. The final sample comprised data from 32,981 students and 875 schools in six CHCs (Singapore, Hong Kong, Taipei, Korea, Macau, and Japan) and data from 83,527 students and 3,468 schools in nine non-CHCs (Switzerland, Netherlands, Estonia, Finland, Canada, Poland, Belgium, Germany, and Australia).

PISA 2012 was sponsored internationally by the OECD, and coordinated and administered internationally by the PISA international consortium, led by the Australian Council for Educational Research. All participating economies followed standardized procedures outlined in the technical standards and manuals provided.

\section{Measures}

Data on the following variables from the PISA 2012 dataset were used in the analysis.

Reading achievement. Student reading, mathematics, and science achievement was assessed in PISA 2012. Students were not administered the complete set of test items by design, and therefore each item had missing responses. This made it impossible to estimate achievement scores for each student. To overcome this limitation, PISA 2012 aggregated the results of individual students to produce scores for groups of students. For each student then, the estimated distribution of achievement scores (e.g., reading) of students similar to him or her in terms of responses to the assessment and background items was represented by a set of five 'plausible values' (PVs; OECD 2014). The present study used student reading PVs as measures of student achievement (OECD 2014). However, there is an inherent measurement error because these PV scores were estimated. To account for the measurement error, the present analysis used HLM7 (Raudenbush, Bryk, Cheong, Congdon, and du Tolt 2011) which 
first estimated parameters for each of the five PVs before averaging the estimates in the hierarchical linear modelling (HLM) analysis (to be described later). HLM7 then combined the average of the sampling error from the five PVs with the variance between them multiplied by a factor related to the number of PVs.

Parental education. Student familial institutional cultural capital was measured using the PISA 2012 index measuring the highest educational level of fathers (FaEdu) and mothers (MoEdu) derived from student responses to items asking about their parents' educational attainment $(0=$ None $; 1=$ Primary education $; 2=$ Lower secondary education $; 3=$ Vocational/pre-vocational upper secondary; 4 = General upper secondary or non-tertiary post -secondary; 5 = Vocational tertiary education; $6=$ Theoretically oriented tertiary and post-graduate) - see OECD (2014).

Home educational and cultural resources. Student familial objectified cultural capital was measured using two PISA's Rasch calibrated scales (OECD 2014). The first scale (HomeEdRes) was derived from data on their access ('Yes', 'No') to seven types of home resources that facilitated their learning (study desk, quiet place to study, school-related books, reference books, dictionary, computer for school work, and educational software). The second scale (HomeCul) was derived from data on their access ('Yes', 'No') to three types of home cultural resources (classic literature, poetry books, and art works).

Controls. Three control variables were included in the HLM analysis. First, a studentlevel dummy variable measuring student sex (Male) was coded as 0 for female (49.5\%) and 1 for male (50.5\%) students. Student sex was included as a control variable because boys and girls may have experienced different socialization in terms of expectations and opportunities, and the socialization could in turn contribute to gender differences in academic achievement (Dumais 2002; Mickelson 2003). Next, school principals responded to 12 items (e.g., 'Selecting teachers for hire') on whether they themselves, teachers, school governing board, 
regional/local education authority, and/or national education authority had a considerable responsibility for different tasks. The degree of autonomy schools enjoy in their decisionmaking (SchAutonomy) was measured using PISA's Rasch calibrated scale derived from these responses indicating that principals, teachers, and/or school governing board (as opposed to regional/local and/or national education authority) were responsible for these tasks (OECD 2014). Country GDP measured on a purchasing power parity basis in 2012 (World Bank 2015) was indicative of a country's level of economic development and included as a control variable at the country level.

Descriptive statistics of the variables are summarized in Table 1.

Table 1 here

\section{Multiple imputation}

Missing values may compromise estimation efficiency and produce biased results. Therefore, the Markov chain Monte Carlo multiple imputation was employed to address the methodological challenge arising from missing values in the variables. This multiple imputation procedure is a generally more effective method of data imputation as compared to other missing values treatment procedures, and especially useful for large samples or in data with higher percentages of missing values (Cheema 2014). The multiple imputation procedure imputed missing values five times, thereby producing multiple complete data sets. In the present study, the pooled parameter estimates (across the five imputed datasets) are analysed. The standard errors of the estimates are unbiased when this procedure is used. 
Three-level fixed effect HLM with full maximum likelihood estimation was performed using HLM7 (Raudenbush et al. 2011) to examine the relationship between student cultural capital and reading achievement. In the analysis, the independent variables were standardized before inclusion in the HLM to facilitate meaningful comparison of the regression parameters. Senate weights at the student and school levels were also incorporated in the HLM.

Four HLM models (with random intercepts) were fitted separately for CHCs and nonCHCs (see Appendix for model specifications). Model 1 ascertained the proportion of student achievement variance at the student, school, and country levels. Model 2 included the various control variables. Model 3 examined if parental educational attainment was related to student achievement after accounting for the control variables. Model 4 examined if home educational and cultural resources were related to student achievement after accounting for the control variables and parental educational attainment.

\section{Results}

\section{Mean levels of reading achievement and cultural capital}

T-test results (Table 1) showed that student mean levels of reading achievement $($ ReadPV1, $\mathrm{t}(61,602.79)=37.71 ;$ ReadPV2, $\mathrm{t}(62,004.38)=37.36 ;$ ReadPV3, $\mathrm{t}(61,732.02)=$ 38.07; ReadPV4, $\mathrm{t}(61,695.83)=37.71 ; \operatorname{ReadPV} 5, \mathrm{t}(61,756.44)=37.88)$ were significantly higher in CHCs as compared to non-CHCs, $p<.001$. However, the mean levels of the four cultural capital indicators $($ FaEdu, $\mathrm{t}(50,770.79)=-42.83 ;$ MoEdu, $\mathrm{t}(52,919.62)=-63.91$; HomeEdRes, $\mathrm{t}(59,799.90)=-45.31 ;$ HomeCul, $\mathrm{t}(57,348.18)=-17.51)$ were significantly lower in CHCs as compared to non-CHCs, $p<.001$. 
Table 1 here

\section{HLM for CHCS}

HLM Model 1 results (Table 2) for CHCs showed that the student reading achievement variance accrued at student (level $1-60.08 \%$ ), school (level $2-37.92 \%$ ), and country (level $3-2.00 \%$ ) levels, thereby validating the utility of using HLM for the present analysis. Results from Model 2 showed that boys ( $\mathrm{z}($ Male), $\pi=-13.65)$, as compared to girls, had lower levels of reading achievement, $p<.001$. In contrast, the level of school autonomy ( $\mathrm{z}($ SchAutonomy), $\beta=0.82, \mathrm{p}=0.81)$ and economic development of countries $(\mathrm{z}(\mathrm{GDPppp}), \gamma$ $=-4.41, p=0.33$ ) were not significantly related to student achievement.

Model 3 examined the contribution of parental educational attainment to student achievement. Results showed that students who had more highly educated fathers (z(FaEdu), $\pi=4.94, p<.001)$ and mothers $(\mathrm{z}(\mathrm{MoEdu}), \pi=2.66, p<.01)$ had higher levels of reading achievement. These results suggest that paternal education might be more strongly associated with student achievement than maternal education.

Model 4 examined the contribution of students' access to home educational and cultural resources to their reading achievement after controlling for parental education and other variables. Results showed that paternal education continued to be related to student achievement although the strength of association was weaker than that in Model 3, while maternal education was not related to student achievement. Students who had access to more home educational (z(HomeEdRes), $\pi=7.21)$ and cultural $(\mathrm{z}(\mathrm{HomeCul}), \pi=7.69)$ had higher levels of achievement, $p<.001$ level. These results suggest that the effects of parental education on student achievement were mediated through the provision of home educational and cultural resources to their children. Comparison of the standardised regression 
coefficients indicated that access to home cultural and educational resources might be more consequential to student achievement than paternal education.

Table 2 here

\section{HLM for non-CHCs}

HLM Model 1 results (Table 3) for non-CHCs showed that the student reading achievement variance accrued at student (level $1-54.12 \%$ ), school (level $2-42.70 \%$ ), and country (level $3-3.19 \%$ ) levels, thereby validating the utility of using HLM for the present analysis. Results from Model 2 showed that boys (z(Male), $\pi=-18.50$ ), as compared to girls, had lower levels of reading achievement, $p<.001$. Students from schools with higher levels of autonomy had higher levels of achievement ( $\mathrm{z}(\operatorname{Sch}$ Autonomy), $\beta=6.65, p<.01)$ but economic development of countries (z(GDPppp), $\gamma=-23.99, p=0.07)$ was not significantly related to student achievement.

Model 3 examined the contribution of parental educational attainment to student achievement. Results showed that students who had more highly educated fathers (z(FaEdu), $\pi=5.93)$ and mothers $(\mathrm{z}(\mathrm{MoEdu}), \pi=7.28)$ had higher levels of reading achievement, $p<$ .001 . These results suggest that there might be a stronger association between maternal, as compared to paternal, education and student achievement.

Model 4 examined the contribution of students' access to home educational and cultural resources to their reading achievement after controlling for parental education and other variables. Results showed that both paternal and maternal education continued to be related to student achievement although the strength of association was weaker than that in Model 3. Students who had access to more home educational (z(HomeEdRes), $\pi=3.52)$ and cultural (z(HomeCul), $\pi=9.29)$ had higher levels of achievement, $p<.001$ level. These 
results suggest that the effects of parental education on student achievement might be mediated through the provision of home educational and cultural resources to their children. Comparison of the standardised regression coefficients indicated that access to home cultural resources might be more consequential to student achievement than maternal education, paternal education, or access to home educational resources.

Comparison of the standardised regression coefficients for the cultural capital indicators in Model 4 suggested that paternal education, maternal education, and access to home cultural resources might be less strongly related to student reading achievement in CHCs than in non-CHCs. However, access to home educational resources appeared to be more strongly related to student achievement in CHCs than in non-CHCs.

Table 3 here

\section{Discussion and conclusion}

Results from the present multilevel modelling study examining secondary school students $(N=116,508)$ from 4,343 school in six CHCs and nine non-CHCs showed that access to cultural capital was generally positively associated with student achievement in both groups of countries. However, the levels of institutionalized and objectified cultural capital for students were lower in CHCs as compared to non-CHCs, and the relationships between the different indicators of cultural capital (except home educational resources) and student reading achievement might be weaker in $\mathrm{CHCs}$ than in non-CHCs.

\section{Sociocultural values on education}

The weaker associations between cultural capital and student achievement in CHCs (vis-a-vis non-CHCs) suggest that family backgrounds might be less deterministic in these 
countries. Many reasons could account for these results. The present study attempted to minimize the influence of some key competing factors in two ways so that any differences in the associations could then be more likely, though not exclusively, to be attributed to sociocultural norms on education. First, two sets of countries comparable in their levels of educational development (as measured by student mean levels of reading, mathematics, and science achievement equal to or above the OECD means, share of low mathematics achievers less than OECD mean, and share of high mathematics achievers above OECD mean) and economic development (as measured by classification of countries as high or very high income countries) were compared. Second, the levels of school autonomy (SchAutonomy), constituting another important measure of differences in education systems, and country's GDP on a purchasing power parity basis (GDPppp) were statistically controlled in the HLM. The inclusion of these controls enabled us to ascertain the relationships between different cultural capital indicators and student achievement, net of school autonomy and national GDP among CHCs, and separately among non-CHCs which had similar levels of mean student achievement and high/very high national income levels. The differences in the strength of the relationships between cultural capital and student achievement evident in the HLM results are then inferred from prior conceptualization to be attributable to the moderating influence of sociocultural values that support education in $\mathrm{CHCs}^{1}$. For example in $\mathrm{CHCs}$, these values include a deep seated belief in effort and perseverance in learning as opposed to innate intelligence, and the strategic importance of school achievement as a way of honouring parents and for social mobility (Chan et al. 2009; French et al. 2015; Lee 2010; Li et al. 2010; Sun 2011; Wang et al. 2012). Given the different strength of association between cultural capital and student achievement in CHCs versus non-CHCs and the plausible sociocultural reasons that may explain the relationship, the results provide tentative indications that $\mathrm{CHCs}$

\footnotetext{
${ }^{1}$ Other explanations for the demonstrated differences in the relationships between cultural capital and student achievement in CHCs and in non-CHCs (e.g., historical or political reasons) are plausible but not examined in this study due to the lack of data in PISA 2012. This limitation is reiterated in the conclusion.
} 
and non-CHCs may constitute different social fields where cultural advantages function differently (Bourdieu 1990; O’Donoghue 2013; Tan 2015, 2017; Thomson 2012). The concept of social field in cultural capital theory has been examined in different student and institutional areas such as informal academic standards, use of linguistic resources, school tracking, parental school involvement, college decision-making, college financial aid, and college student development (Winkle-Wagner 2010). In contrast, few scholars have identified different countries with different sociocultural values and norms as fields (Winkle-Wagner 2010). Therefore, the present study extends our knowledge of social fields in cultural capital theory.

Interestingly, the normative nature of these sociocultural values in $\mathrm{CHCs}$ relates well with the notion of embodied dispositions in cultural capital theory. The conjecture that sociocultural and individual dispositions may affect student outcomes resonates with Bourdieu's conception of embodied dispositions as habitus (Reay 2004a). More specifically, Reay (2004a) argued that habitus is 'a multi-layered concept, with more general notions of habitus at the level of society and more complex, differentiated notions at the level of the individual' (Reay 2004a, 434). Habitus is embodied in students and is shaped by their present and past experiences in the social field (Reay 2004a). Most importantly, it is generative in that it enables students to identify possibilities and opportunities while also recognize prohibitions in the social field (Bourdieu 1990).

The unexpected finding that access to home educational resources might be more highly associated with student achievement in $\mathrm{CHCs}$ than in non-CHCs is intriguing. The results also indicated that access to home educational and cultural resources appeared to be more important than parental education for student achievement in CHCs. These results provided support for contenders (Jaeger 2009; Lareau and Weininger 2003; Prieur and Savage 2013) that cultural capital could include more than highbrow arts appreciation and 
participation (as alluded to in access to home cultural resources) to include linguistic and cognitive habits, knowledge, and skills (as alluded to in access to home educational resources). The latter resources are propitious to educational practices such as reading and parental involvement in children's learning, and therefore more indicative of parental familiarity with school evaluative standards (Lareau and Weininger 2003). Indeed, some scholars argued that cultural capital must command value in the field, so these educational practices may be more legitimate and relevant markers of social distinction in some societies (Farkas, Grobe, Sheehan, and Shuan 1990; Reay 2004b; Vryonides 2007), especially those with high levels of societal emphasis on academic success and the proliferation of high-stake examinations in many CHCs.

\section{Relative contributions of different cultural capital indicators}

The findings on differences in the association between cultural capital and student achievement in $\mathrm{CHCs}$ versus non-CHCs are also interesting. There are previous studies that examine the relative importance of the different forms of cultural capital (Kraaykamp and van Eijck 2010), but the knowledge base is still evolving as to why some forms are more important than others in predicting student achievement. Two sets of comparisons from the present study will be discussed here.

First, the results suggest that objectified cultural capital, both cultural and educational, might be more important than institutionalized cultural capital for student achievement in CHCs. This pattern of finding was not found in the case of non-CHCs where only access to home cultural resources appeared to be more strongly associated with student achievement than parental education. These findings imply that intergenerational transmission of advantage in education is not an automatic process. It is not sufficient for children to merely be associated with highly qualified parents. Rather, parents should use their socioeconomic 
resources to invest in home educational and cultural resources in order to benefit their children's learning in school. In CHCs in particular, investment in home resources by parents who could be from different social origins, as compared to parental education could be indicative of the ubiquitous sociocultural norms underscoring achievement in these societies. These norms include beliefs that every child regardless of innate ability can achieve if they put in effort in their learning (Sun 2011; Wang et al. 2012), that learning yields long-term benefits that are more worthwhile than short-term gratification (French et al. 2015), and that academic achievement will bring honour to one's parents (Chan et al. 2009; Li et al. 2010). Another implication of this finding underscoring the lesser importance of parental education as compared to home resource access in $\mathrm{CHCs}$ is that there is more policy leverage for policymakers to provide students with learning resources and opportunities so as to improve their learning. This policy option may be less effective in non-CHCs given that access to home educational resources could be the least beneficial for student achievement among the four cultural capital indicators.

Second, the most important cultural capital variable for student achievement appeared to be access to home cultural resources in $\mathrm{CHCs}$ (and non-CHCs). This finding could mean that highbrow culture is still relevant in many societies as discussed earlier. It could also arise because the dependent achievement variable measured in the present study was reading, as opposed to mathematics or science. More specifically, reading achievement may be more susceptible to subjective and stylistic variables (e.g., teacher perceptions) than achievement in mathematics or science (Tan 2017). Therefore, teachers may have inflated perceptions of student levels of linguistic competence due to the latter's demonstration of cultural competence. 


\section{Contributions}

The present study makes two important contributions to the literature on cultural capital theory. First, it provides evidence that cultural capital resources as a pluralistic construct differ in their relative contributions to student achievement. More specifically, the present study chose the measurement strategy of using the same set of cultural capital indicators to enable the meaningful comparison of the relationships between cultural capital and student achievement in two groups of countries, namely $\mathrm{CHCs}$ and non-CHCs. This strategy presupposed that the same set of indicators is relevant in these countries, an assumption that could be tested in future studies. The results suggest that the different indicators of cultural capital (institutionalized and objectified) could have varying contributions to student achievement, both within and between groups of similar countries such as CHCs and non-CHCs. These results add to a growing literature indicating that cultural capital effects are complex and nuanced (Jaeger 2009; Kraaykamp and van Eijck 2010; Tan 2017).

The second contribution of the present study emanates from results suggesting that CHCs and non-CHCs do in fact constitute social fields where cultural capital may operate differently. It appears that the achievement of students in CHCs may be less influenced by their cultural capital than peers in non-CHCs. Indeed, the results suggest that contextual variables such as sociocultural beliefs and norms in CHCs may have moderated the effects of cultural capital on student achievement. These results affirm that cultural capital theory does indeed have transcultural value (Robbins 2004) although cultural resources may have different degrees of influence on student outcomes in different contexts (Byun et al. 2012; Caro and Lenkeit 2012; French et al. 2015; Ker 2016; Lee 2014; Mendez 2015).

\section{Limitations and future research}


As with all studies, the present study suffers from some limitations. The first key limitation pertains to what Justin and colleagues (2000) termed 'naïve empiricism'. More specifically, studies may suffer from naïve empiricism if researchers oversimplify complex phenomena and make unwarranted conclusions based on empirical observations. In the context of the present study, it is assumed that access to valued cultural capital resources will benefit student achievement in a particular social field (Bourdieu 1990; O'Donoghue 2013; Thomson 2012). However, detection of significant associations between cultural capital variables and student achievement (i.e., correlations) should not be regarded as evidence of a causal relation. In a related vein, an effort was made to compare only countries with relatively comparable levels of educational and economic development, and to statistically account for effects of school autonomy on student achievement and national economic development in the present study. The objective is to enable differences on the contribution of cultural capital to student achievement detected to be more plausibly attributed to the different sociocultural values prevailing in $\mathrm{CHCs}$ and non-CHCs. However, this inference while reasonable is not without qualifications, due to the non-experimental nature of the study and because there was no available data to control for other influences (e.g., political and historical) that may impinge on student achievement. Future research could employ qualitative methodologies to investigate why and how cultural values may moderate the relationship between cultural capital and student achievement in different countries. The second limitation is that the present study only examines institutionalized and objectified cultural capital indicators due to the availability of variables in the PISA 2012 dataset. Future research may examine potential differences in the relationship between embodied cultural capital and student achievement in different countries. The third limitation pertains to the small number of countries in the HLM analysis. This may have affected the ability to detect country-level effects (e.g., Country GDP) 
in the HLM (Snijders 2005) that we would have otherwise expected from previous studies (e.g., Chiu and Chow 2010). 


\section{References}

Baker, Claire E. 2014. “African American Fathers' Contributions to Children's Early Academic Achievement: Evidence from Two-parent Families from the Early Childhood Longitudinal Study - Birth Cohort.” Early Education \& Development 25(1): $19-35$.

Baker, Claire E. 2015. "Does Parent Involvement and Neighbourhood Quality Matter for African American Boys' Kindergarten Mathematics Achievement?” Early Education and Development 26(3): 342-355.

Baker, Claire E., Claire E. Cameron, Sara E. Rimm-Kaufman, and David Grissmer. 2012. "Family and Sociodemographic Predictors of School Readiness Among African American Boys in Kindergarten.” Early Education \& Development 23(6): 833-854.

Baker, David P., Brian Goesling, and Gerald K. LeTendre. 2002. "Socioeconomic Status, School Quality, and National Economic Development: A Cross-national Analysis of the "Heyneman-Loxley Effect" on Mathematics and Science Achievement." Comparative Education Review 46(3): 291-312.

Bourdieu, Pierre. 1984. Distinction: A Social Critique of the Judgement of Taste. Cambridge, MA: Harvard University Press.

Bourdieu, Pierre. 1986. “The Forms of Capital.” In Handbook of Theory and Research for the Sociology of Education, edited by John G. Richardson, 241-258. Westport, CT: Greenwood.

Bourdieu, Pierre. 1990. The Logic of Practice. Stanford, CA: Stanford University Press.

Bourdieu, Pierre, and J. C. Passeron. 1977. Reproduction in Education, Society and Culture. London, UK: Sage.

Byun, Soo-yong, Evan Schofer, and Kyung-keun Kim. 2012. "Revisiting the Role of Cultural 
Capital in East Asian Educational Systems: The Case of South Korea.” Sociology of Education 85(3): 219-239.

Caro, Daniel H. and Jenny Lenkeit. 2012. “An Analytical Approach to Study Educational Inequalities: 10 Hypothesis Tests in PIRLS 2006.” International Journal of Research \& Method in Education 35(1): 3-30.

Caro, Daniel H., Andres Sandoval-Hernández, and Oliver Lüdtke. 2013. “Cultural, Social, and Economic Capital Constructs in International Assessments: An Evaluation Using Exploratory Structural Equation Modelling." School Effectiveness and School Improvement 25(3): 433-450.

Chan, Siu-Mui, Jennifer Bowes, and Shirley Wyver. 2009. “Chinese Parenting in Hong Kong: Links among Goals, Beliefs and Styles.” Early Child Development and Care 179(7): $849-862$.

Cheema, Jehanzeb R. 2014. “A Review of Missing Data Handling Methods in Education Research.” Review of Educational Research 84(4): 487-508.

Chiu, Ming Ming, and Bonnie Wing Yin Chow. 2010. “Culture, Motivation, and Reading Achievement: High School Students in 41 Countries." Learning and Individual Differences 20: 579-592.

Chiu, Ming-ming, and Catherine McBride-Chang. 2010. "Family and Reading in 41 Countries: Differences across Cultures and Students." Scientific Studies of Reading 14(6): 514-543.

Claro, Magdalena, Tania Cabello, Ernesto San Martín, and Miguel Nussbaum. 2015. “Comparing Marginal Effects of Chilean Students' Economic, Social and Cultural Status on Digital versus Reading and Mathematics Performance." Computers \& Education 82: 1-10.

Dennis, David. 2000. "The Role of Historical Studies in Mathematics and Science 
Educational Research." In Handbook of Research Design in Mathematics and Science Education, edited by Anthony E. Kelly and Richard A. Lesh, 799-814. Mahwah, NJ: Lawrence Erlbaum.

Dumais, Susan A. 2002. "Cultural Capital, Gender, and School Success: The Role of Habitus." Sociology of Education 75: 44-68.

Hong Kong Education Commission. 2000. Learning for Life, Learning through Life: Reform Proposals for the Education System in Hong Kong. Hong Kong: Education Commission.

Farkas, George, Robert P. Grobe, Daniel Sheehan, and Yuan Shuan. 1990. "Cultural Resources and School Success: Gender, Ethnicity, and Poverty Groups within an Urban School District.” American Sociological Review 55: 127-142.

French, Joseph, Atchaporn French, and Wei-Xuan Li. 2015. "The Relationship among Cultural Dimensions, Education Expenditure, and PISA Performance.” International Journal of Educational Development 44: 25-34.

Grenfell, M. James. 2007. Pierre Bourdieu: Education and Training (Vol. 2). London, UK: Continuum.

Han, Soong-hee, and Atsushi Makino. 2013. "Learning Cities in East Asia: Japan, the Republic of Korea and China.” International Review of Education 59: 443-468. Hanushek, Eric A, and Ludger Woessmann. 2017. "School Resources and Student Achievement: A Review of Cross-Country Economic Research.” In Cognitive Abilities and Educational Outcomes : A Festschrift in Honour of Jan-Eric Gustafsson, edited by Monica Rosén, Kajsa Yang Hansen, and Ulrika Wolff, 149-171: Cham, Switzerland: Springer.

Hansson, Åse, and Jan-Eric Gustafsson. 2013. "Measurement Invariance of Socioeconomic Status across Migrational Background." Scandinavian Journal of Educational 
Research 57(2): 148-166.

Heyneman, Stephen, and William A. Loxley. 1983. "The Effect of Primary-School Quality on Academic Achievement Across Twenty-nine High- and Low-Income Countries.” American Journal of Sociology 88(6): 1162-1194.

Iruka, Iheoma, Aryn Dotterer, and Elizabeth Pungello. 2014. "Ethnic Variations of Pathways Linking Socioeconomic Status, Parenting, and Preacademic Skills in a Nationally Representative Sample." Early Education and Development 25(7): 973-994.

Jæger, Mads Meier. 2009. "Equal Access but Unequal Outcomes: Cultural Capital and Educational Choice in a Meritocratic Society.” Social Forces 87(4): 1943-1971. Juslin, Peter, Anders Winman, and Henrik Olsson. (2000) "Naive Empiricism and Dogmatism in Confidence Research: A Critical Examination of the Hard-easy Effect." Psychological Review 107(2): 384-396.

Ker, H. W. 2016. “The Impacts of Student-, Teacher- and School-level Factors on Mathematics Achievement: An Exploratory Comparative Investigation of Singaporean Students and the USA Students.” Educational Psychology 36(2): 254-276.

Kraaykamp, Gerbert, and Koen van Eijck. 2010. “The Intergenerational Reproduction of Cultural Capital: A Threefold Perspective.” Social Forces 89(1): 209-232.

Lam, Chi-chung, Esther Sui-chu Ho, and Ngai-ying Wong. 2002. "Parents' Beliefs and Practices in Education in Confucian Heritage Cultures: The Hong Kong Case.” Journal of Southeast Asian Education 3(1): 99-114.

Lareau, Annette, and Elliot B. Weininger. 2003. "Cultural Capital in Educational Research: A Critical Assessment." Theory \& Society 32: 567-606.

Lee, Jihyun. 2014. "Universal Factors of Student Achievement in High-performing Eastern and Western Countries." Journal of Educational Psychology 106(2): 364-374.

Lee, Yoonmi. 2010. "Views on Education and Achievement: Finland's Story of Success and 
South Korea's Story of Decline.” KEDI Journal of Educational Policy 7(2): 379-401.

Lenkeit, Jenny, Daniel H. Caro, and Steve Strand. 2015. "Tackling the Remaining Attainment Gap between Students with and without Immigrant Background: An Investigation into the Equivalence of SES Constructs." Educational Research and Evaluation 21(1): 6083.

Li, Yan, Philip Costanzo, and Martha Putallaz. 2010. "Maternal Socialization Goals, Parenting Styles, and Social-emotional Adjustment among Chinese and European American Young Adults: Testing a Mediation Model." The Journal of Genetic Psychology 171(4): 330-362.

Little, Angela, and Caine Rolleston. 2014. "School Quality Counts: Evidence from Developing Countries." Oxford Review of Education 40(1): 1-9.

Mendez, Ildefonso. 2015. "The Effect of the Intergenerational Transmission of Noncognitive Skills on Student Performance.” Economics of Education Review 46: 78-97.

Mickelson, R. A. 2003. “Gender, Bourdieu, and the Anomaly of Women's Achievement Redux.” Sociology of Education 76(4): 373-375.

Mourshed, Mona, Chinezi Chijioke, and Michael Barber. 2010. How the World's Most Improved School Systems Keep Getting Better. file:///C:/Users/User/Downloads/How-

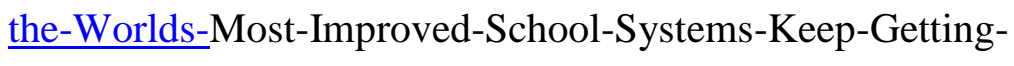
Better_Downloadversion_Final.pdf.

Nguyen, Phuong-mai, Cees Terlouw, and Albert Pilot. 2006. “Culturally Appropriate Pedagogy: The Case of Group Learning in a Confucian Heritage Culture Context.” Intercultural Education 17(1): 1-19.

O’Donoghue, Mary. 2013. "Putting Working-class Mothers in their Place: Social Stratification, the Field of Education, and Pierre Bourdieu's Theory of Practice." British Journal of Sociology of Education 34(2): 190-207. 
OECD. 2013. PISA 2012 Results in Focus: What 15-year-olds Know and What They Can Do with What They Know. http://www.oecd.org/pisa/keyfindings/pisa-2012-resultsoverview.pdf

OECD. 2014. PISA 2012 Technical Report. https://www.oecd.org/pisa/pisaproducts/PISA-2012-technical-report-final.pdf OECD. 2015. Universal Basic Skills: What Countries Stand to Gain. http://dx.doi.org/10.1787/9789264234833-en .

Prieur, Annick, and Mike Savage. 2013. “Emerging Forms of Cultural Capital.” European Societies 15(2): 246-267.

Rao, Nirmala, Kai-ming Cheng, and Kirti Narain. 2003. "Primary Schooling in China and India: Understanding How Socio-Contextual Factors Moderate the Role of the State.” International Review of Education 49(1-2): 153-176.

Raudenbush, Stephen, Anthony Bryk, Yuk Fai Cheong, Richard Congdon, and Mathilda du Toit. 2011. HLM7: Hierarchical Linear and Nonlinear Modeling. Lincolnwood, IL: Scientific Software International.

Reay, Diane. 2004a. “'It's All Becoming a Habitus': Beyond the Habitual Use of Habitus in Educational Research.” British Journal of Sociology of Education 25(4): 431-444.

Reay, D. 2004b. "Education and Cultural Capital: The Implications of Changing Trends in Education Policies." Cultural Trends 13(2): 73-86.

Robbins, Derek. 2004. “The Transcultural Transferability of Bourdieu's Sociology of Education.” British Journal of Sociology of Education 25(4): 415-430.

Rutkowski, David, and Leslie Rutkowski. 2013. "Measuring Socioeconomic Background in PISA: One Size Might Not Fit All." Research in Comparative and International Education 8(3): 259-278.

Snijders, Tom A.B. 2005. "Power and Sample Size in Multilevel Linear Models". In 
Encyclopedia of Statistics in Behavioral Science (Volume 3), edited by Brian S.

Everitt and David C. Howell, 1570-1573. Chicester: Wiley.

Sun, Miao-tao. 2011. "Educational Research in Mainland China: Current Situation and

Developmental Trends." Comparative Education 47(3): 315-325.

Tan, Cheng Yong. 2013. “Organizational Legitimacy of the Singapore Ministry of Education." Oxford Review of Education 39(5): 590-608.

Tan, Cheng Yong. 2015. “The Contribution of Cultural Capital to Students' Mathematics Achievement in Medium and High Socioeconomic Gradient Economies.” British Educational Research Journal 41(6): 1050-1067.

Tan, Cheng Yong. 2017. "Conceptual Diversity, Moderators, and Theoretical Issues in Quantitative Studies of Cultural Capital Theory." Educational Review. DOI: $10.1080 / 00131911.2017 .1288085$

Thomson, Patricia. 2012. "Field.” In Pierre Bourdieu: Key Concepts, edited by Michael Grenfell, 65-80. Durham, UK: Acumen.

Tran, Thi Tuyet. 2013. "Is the Learning Approach of Students from the Confucian Heritage Culture Problematic?” Educational Research for Policy and Practice 12(1): 57-65. Vryonides, Marios. 2007. "Social and Cultural Capital in Educational Research: Issues of Operationalisation and Measurement.” British Educational Research Journal 33(6): $867-885$.

Wang, Yi, Richard Harding, and Li-wei Mai. 2012. "Impact of Cultural Exposure on Young Chinese Students' Adaptation in a UK Business School.” Studies in Higher Education 37(5): 621-639.

Winkle-Wagner, Rachelle. 2010. "Uses and Abuses of Cultural Capital in Educational Research.” ASHE Higher Educational Report 36(1): 23-57.

World Bank. 2015. GDP per Capita, PPP (Current International \$). 
http://data.worldbank.org/indicator/NY.GNP.PCAP.PP.CD/countries

Zhang, Liang, Gulab Khan, and Armend Tahirsylaj. 2015. "Student Performance, School Differentiation, and World Cultures: Evidence from PISA 2009.” International Journal of Educational Development 42: 43-53.

Zhao, Ning-ning, Martin Valcke, Annemie Desoete, and JeanPierre Verhaeghe. 2012. "The Quadratic Relationship between Socioeconomic Status and Learning Performance in China by Multilevel Analysis: Implications for Policies to Foster Education Equity.” International Journal of Educational Development 32(3): 412-422. 


\section{Research Ethics Statement}

The present study has obtained ethics approval from the Human Research Ethics Committee (HREC) at The University of Hong Kong (HREC's reference number: EA1511010). 
Table 1. Summary of descriptive statistics.

\begin{tabular}{|c|c|c|c|c|c|c|}
\hline & \multicolumn{2}{|c|}{$\begin{array}{c}\text { All countries } \\
\text { (116,508 students, } \\
\text { 4,343 schools, } \\
15 \text { countries })\end{array}$} & \multicolumn{2}{|c|}{$\begin{array}{c}\text { CHCs } \\
\text { (32,981 students, } \\
875 \text { schools, } \\
6 \text { countries })\end{array}$} & \multicolumn{2}{|c|}{$\begin{array}{c}\text { Non-CHCs } \\
\text { (83,527 students, } \\
\text { 3,468 schools, } \\
9 \text { countries) }\end{array}$} \\
\hline & $M(S D)$ & \%Missing & $M(S D)$ & $S E$ & $M(S D)$ & $S E$ \\
\hline \multicolumn{7}{|c|}{ Reading achievement } \\
\hline ReadPV1 & $514.54(94.64)$ & 0 & $530.93(92.68)$ & 0.51 & $508.07(94.63)$ & 0.33 \\
\hline ReadPV2 & $514.54(94.69)$ & 0 & $530.74(92.26)$ & 0.51 & $508.14(94.87)$ & 0.33 \\
\hline ReadPV3 & $514.67(64.60)$ & 0 & $531.19(92.47)$ & 0.51 & $508.15(94.64)$ & 0.33 \\
\hline ReadPV4 & $514.42(94.61$ & 0 & $530.79(92.53)$ & 0.51 & $507.95(94.64)$ & 0.33 \\
\hline ReadPV5 & $514.46(94.77)$ & 0 & $530.93(92.61)$ & 0.51 & $507.96(94.83)$ & 0.33 \\
\hline \multicolumn{7}{|l|}{ Cultural capital } \\
\hline FaEdu & $4.20(1.57)$ & 7.91 & $3.86(1.73)$ & 0.01 & $4.34(1.47)$ & 0.01 \\
\hline MoEdu & $4.24(1.52)$ & 5.08 & $3.76(1.63)$ & 0.01 & $4.43(1.43$ & 0.01 \\
\hline HomeEdRes & $-0.02(1.00)$ & 1.97 & $-0.23(0.99)$ & 0.01 & $0.06(0.99)$ & 0.00 \\
\hline HomeCul & $-0.14(1.00)$ & 2.96 & $-0.23(1.03)$ & 0.01 & $-0.11(0.98)$ & 0.00 \\
\hline
\end{tabular}

Other variables

$\begin{array}{lcccccc}\text { SchAutonomy } & 0.06(0.88) & 1.90 & 0.28(0.99) & 0.01 & -0.03(0.82) & 0.00 \\ \text { GDPpp } & 47,181.21(21,080.37) & 5.19 & 64,109.92(35,339.78) & 215.33 & 41,722.20(7,921.13) & 27.41\end{array}$

Note. Standard deviations in parentheses. 
Table 2. Fixed effects estimates (top) and variance-covariance estimates (bottom) for models of the predictors of reading achievement in CHCs.

\begin{tabular}{|c|c|c|c|c|}
\hline Parameter & Model 1 & Model 2 & Model 3 & Model 4 \\
\hline \multicolumn{5}{|c|}{ Fixed effects } \\
\hline Intercept & $512.04 * * *(7.41)$ & $518.02 * * *(6.10)$ & $519.54 * * *(6.07)$ & $521.38 * * *(5.57)$ \\
\hline \multicolumn{5}{|l|}{ Student level } \\
\hline z(Male) & & $-13.65 * * *(0.67)$ & $-13.80 * * *(0.67)$ & $-12.95 * * *(0.67)$ \\
\hline $\mathrm{z}(\mathrm{FaEdu})$ & & & $4.94 * * *(0.81)$ & $2.95 * * *(0.82)$ \\
\hline $\mathrm{z}(\mathrm{MoEdu})$ & & & $2.66 * *(0.84)$ & $1.09(0.83)$ \\
\hline z(HomeEdRes) & & & & $7.21 * * *(0.75)$ \\
\hline $\mathrm{z}(\mathrm{HomeCul})$ & & & & $7.69 * * *(0.97)$ \\
\hline \multicolumn{5}{|l|}{ School level } \\
\hline z(SchAutonomy) & & $0.82(3.32)$ & $0.50(3.23)$ & $-0.15(3.06)$ \\
\hline \multicolumn{5}{|l|}{ Country level } \\
\hline z(GDPppp) & & $-4.41(4.00)$ & $-2.75(4.00)$ & $-2.83(3.69)$ \\
\hline \multicolumn{5}{|c|}{ Random parameters } \\
\hline \multicolumn{5}{|l|}{ Intercepts } \\
\hline Level 1 & $5,382.68$ & $5,239.50$ & $5,208.70$ & $5,092.09$ \\
\hline Level 2 & $3,397.95 * * *$ & $3,268.29 * * *$ & $3,071.22 * * *$ & $2,752.84 * * *$ \\
\hline Level 3 & $179.16^{* * *}$ & $131.56^{* * *}$ & $135.55 * * *$ & $111.26^{* * *}$ \\
\hline \multicolumn{5}{|l|}{$\%$ variance } \\
\hline Level 1 & 60.08 & 60.65 & 61.89 & 64.00 \\
\hline Level 2 & 37.92 & 37.83 & 36.49 & 34.60 \\
\hline Level 3 & 2.00 & 1.52 & 1.61 & 1.40 \\
\hline
\end{tabular}

Note:

Standard errors in parentheses.

$* * * p<.001 . * * p<.01$. 
Table 3. Fixed effects estimates (top) and variance-covariance estimates (bottom) for models of the predictors of reading achievement in non-CHCs.

\begin{tabular}{|c|c|c|c|c|}
\hline Parameter & Model 1 & Model 2 & Model 3 & Model 4 \\
\hline \multicolumn{5}{|c|}{ Fixed effects } \\
\hline Intercept & $496.13 * * *(6.98)$ & $484.43 * * *(6.78)$ & $485.49 * * *(6.61)$ & $486.11 * * *(6.39)$ \\
\hline \multicolumn{5}{|l|}{ Student level } \\
\hline z(Male) & & $-18.50 * * *(0.73)$ & $-18.93 * * *(0.72)$ & $-18.03 * * *(0.72)$ \\
\hline $\mathrm{z}(\mathrm{FaEdu})$ & & & $5.93 * * *(0.83)$ & $4.53 * * *(0.83)$ \\
\hline $\mathrm{z}(\mathrm{MoEdu})$ & & & $7.28 * * *(0.91)$ & $5.53 * * *(0.88)$ \\
\hline z(HomeEdRes) & & & & $3.52 * * *(0.78)$ \\
\hline $\mathrm{z}(\mathrm{HomeCul})$ & & & & $9.29 * * *(0.86)$ \\
\hline \multicolumn{5}{|l|}{ School level } \\
\hline z(SchAutonomy) & & $6.65 * *(2.35)$ & $6.15^{* *}(2.27)$ & $5.67 *(2.21)$ \\
\hline \multicolumn{5}{|l|}{ Country level } \\
\hline z(GDPppp) & & $-23.99(11.06)$ & $-23.32(10.79)$ & $-19.16(10.42)$ \\
\hline \multicolumn{5}{|c|}{ Random parameters } \\
\hline \multicolumn{5}{|l|}{ Intercepts } \\
\hline Level 1 & $5,541.64$ & $5,232.29$ & $5,147.58$ & $5,059.79$ \\
\hline Level 2 & $4,372.17 * * *$ & $4,128.45^{* * *}$ & $3,821.22 * * *$ & $3,630.69^{* * *}$ \\
\hline Level 3 & $326.44 * * *$ & $172.17 * * *$ & $164.82 * * *$ & $152.96^{* * *}$ \\
\hline \multicolumn{5}{|l|}{$\%$ variance } \\
\hline Level 1 & 54.12 & 54.89 & 56.36 & 57.22 \\
\hline Level 2 & 42.70 & 43.31 & 41.84 & 41.06 \\
\hline Level 3 & 3.19 & 1.81 & 1.80 & 1.73 \\
\hline
\end{tabular}

Note:

Standard errors in parentheses.

$* * * p<.001 . * * p<.01 . * p<.05$. 
Model 4 can be mathematically represented as follows:

Level 1 model: $\quad \operatorname{Read}_{i j k}=\pi_{0 j k}+\pi_{l j k} \mathrm{z}(\mathrm{FaEdu})_{i j k}+{ }_{\pi 2 j k} \mathrm{z}(\mathrm{MoEdu})_{i j k}+{ }_{\pi 3 j k}$

$$
\begin{aligned}
& \mathrm{z}(\text { HomeEdRes })_{i j k}+{ }_{\pi 4 j k} \mathrm{z}(\text { HomeCul })_{i j k}+\pi_{5 j k} \mathrm{z}(\text { Male })_{i j k} \\
& +e_{i j k}
\end{aligned}
$$

Level 2 model: $\quad \pi_{0 j k}=\beta_{00 k}+\beta_{01 k} \mathrm{z}(\text { SchAutonomy })_{j k}+r_{0 j k}$

$$
\begin{aligned}
& \pi_{1 j k}=\beta_{10 k} \\
& \pi_{2 j k}=\beta_{20 k} \\
& \pi_{3 j k}=\beta_{30 k} \\
& \pi_{4 j k}=\beta_{40 k} \\
& \pi_{5 j k}=\beta_{50 k}
\end{aligned}
$$

Level 3 model: $\quad \beta_{00 k}=\gamma_{000}+\gamma_{001} \mathrm{z}(\mathrm{GDPppp})_{k}+u_{00 k}$

$$
\begin{aligned}
& \beta_{01 k}=\gamma_{010} \\
& \beta_{10 k}=\gamma_{100} \\
& \beta_{20 k}=\gamma_{200} \\
& \beta_{30 k}=\gamma_{300} \\
& \beta_{40 k}=\gamma_{400} \\
& \beta_{50 k}=\gamma_{500}
\end{aligned}
$$

where Read $=$ Student reading achievement,

$\pi, \beta, \gamma=$ Parameter estimates of level 1,2 , and 3 variables respectively; $e, r, U=$ Variation in estimated student reading achievement within schools, between schools, and between countries; and the subscripts $i, j, k$ correspond to student $i$, school $j$, and country $\mathrm{k}$ respectively. 